\title{
Topiramate-induced weight loss is possibly due to the blockade of conditioned and automatic processes
}

\author{
Yasser Khazaal • Daniele Fabio Zullino
}

Received: 22 March 2007 / Accepted: 23 April 2007 /Published online: 14 July 2007

(C) Springer-Verlag 2007

Sir,

We read with great interest the paper of Tremblay and others [1] on topiramate's effect on weight, energy balance, appetite and satiety. They studied topiramate-induced weight loss (WL) in obese males who were, however, instructed not to start any diet or exercise program intended to induce WL during the course of the study. Most interestingly, the authors investigated among other things the desire to eat, hunger, fullness and prospective food consumption. The WL that clearly appeared during the study could not be explained by a modification of energy expenditure. In absence of any dietary intervention, a general reduction in food intake was observed in patients receiving topiramate. An anorectic effect of topiramate, as reported for other anti-obesity agents [2] was, then, expected. Actually, no variations were found on hunger, fullness or desire to eat under topiramate treatment.

Thus, as neither appetite nor energy expenditure was affected, other mechanisms underlying the food intake process have to be hypothesized as being affected by topiramate. Eating behavior is not only linked to appetite mechanisms but may largely be maintained by a compulsive and/or an addictive component, both of which are generally associated with environmental cues and automatic processes [3]. These processes have been found to depend on the glutamatergic system, where the activation of the $\alpha$ amino-3-hydroxy-5-methyl-4-isoxazolepropionic acid (AMPA) receptor is critical for their expression. The AMPA receptors (AMPAR) antagonists are known to block reinstatement of conditioned and automatic processes [4].

Y. Khazaal · D. F. Zullino $(\square)$

Service d'abus de substances, Hôpitaux Universitaires de Genève,

Rue verte 2 ,

1205 Genève, Switzerland

e-mail: Daniele.Zullino@hcuge.ch
Topiramate has multiple mechanisms of action, including blocking the AMPA/kainate subtype of the glutamate receptor [5]. Given the role of AMPAR in the expression of conditioned responses and topiramate's AMPAR-antagonistic properties, one can hypothesize that topiramate-induced WL, which was not due to modification of energy expenditure nor to an anorectic effect, was possibly mediated by topiramate's effect on conditioned and automatic processes.

This observation is in line with observations on topiramate's effects on various addictive and/or compulsive behaviors such as alcohol addiction [6], nicotine addiction [7], sexual compulsive behavior [8], pathological gambling [9] as well as binge-eating disorder [10]. It could be of high interest to investigate the importance of automatic and conditioned processes in overeating in obese patients who probably could have better response to topiramate treatment.

A further study including an investigation of conditioned and automatic processes in eating, for example by a cognitive and behavioral analysis of eating patterns before and during topiramate treatment, could highlight this subject.

\section{References}

1. Tremblay A, Chaput JP, Berube-Parent S, Prud'homme D, Leblanc C, Almeras N et al (2007) The effect of topiramate on energy balance in obese men: a 6-month double-blind randomized placebo-controlled study with a 6-month open-label extension. Eur J Clin Pharmacol 63(2):123-134

2. Appolinario JC, Bacaltchuk J, Sichieri R, Claudino AM, GodoyMatos A, Morgan C et al (2003) A randomized, double-blind, placebo-controlled study of sibutramine in the treatment of bingeeating disorder. Arch Gen Psychiatry 60(11):1109-1116

3. Fedoroff I, Polivy J, Herman CP (2003) The specificity of restrained versus unrestrained eaters' responses to food cues: general desire to eat, or craving for the cued food? Appetite 41(1):7-13 
4. Backstrom P, Hyytia P (2003) Attenuation of cocaine-seeking behaviour by the AMPA/kainate receptor antagonist CNQX in rats. Psychopharmacology (Berl) 166(1):69-76

5. Gibbs JW III, Sombati S, DeLorenzo RJ, Coulter DA (2000) Cellular actions of topiramate: blockade of kainate-evoked inward currents in cultured hippocampal neurons. Epilepsia 41 (Suppl 1): S10-S16

6. Johnson BA, Ait-Daoud N, Bowden CL, DiClemente CC, Roache JD, Lawson $\mathrm{K}$ et al (2003) Oral topiramate for treatment of alcohol dependence: a randomised controlled trial. The Lancet 361(9370):1677-1685
7. Khazaal Y, Cornuz J, Bilancioni R, Zullino DF (2006) Topiramate for smoking cessation. Psychiatry Clin Neurosci 60(3):384-388

8. Khazaal Y, Zullino DF (2006) Topiramate in the treatment of compulsive sexual behavior: case report. BMC Psychiatry 6:22

9. Dannon PN, Lowengrub K, Gonopolski Y, Musin E, Kotler M (2005) Topiramate versus fluvoxamine in the treatment of pathological gambling: a randomized, blind-rater comparison study. Clin Neuropharmacol 28(1):6-10

10. McElroy SL, Shapira NA, Arnold LM, Keck PE, Rosenthal NR, Wu $\mathrm{SC}$ et al (2004) Topiramate in the long-term treatment of binge-eating disorder associated with obesity. J Clin Psychiatry 65(11):1463-1469 